\title{
Transcriptomic analysis reveals the key immune-related signalling pathways of Sebastiscus marmoratus in response to infection with the parasitic ciliate Cryptocaryon irritans
}

Fei Yin ${ }^{1,2}$ and Dong Qian ${ }^{1,2^{*}}$

\begin{abstract}
Background: False kelpfish (Sebastiscus marmoratus) is one of the target species in artificial breeding in China, and is susceptible to infection by Cryptocaryon irritans, which is an obligate parasitic ciliate that lives in the epithelium of the fish gills, skin and fins. Here, we sought to understand the mechanisms of molecular immunity of S. marmoratus against C. irritans infection.

Methods: We carried out an extensive analysis of the transcriptome of S. marmoratus immune-related tissues. A paired-end library was constructed from the cDNA synthesized using a Genomic Sample Prep Kit. Five normalized cDNA libraries were constructed using RNA from the control group and the four groups of C. irritans-infected fish. The libraries were sequenced on an Illumina Mi-Seq platform, and functional annotation of the transcriptome was performed using bioinformatics software.

Results: The data produced a total of 149,983,397 clean reads from five cDNA libraries constructed from S. marmoratus immune-related tissues. A total of 33,291 unigenes were assembled with an average length of $1768 \mathrm{bp}$. In eggNOG (Evolutionary Genealogy of Genes: non-supervised orthologous groups) categories, 333 unigenes (0. 94\%) were assigned to defense mechanisms. In the immune system process sub-categories of gene ontology (GO) enrichment analysis, with the passage of time post-infection, the number of differentially expressed genes (DEGs) was reduced from $24 \mathrm{~h}$ to $48 \mathrm{~h}$ but then increased from $72 \mathrm{~h}$ to $96 \mathrm{~h}$. Specifically, the immune-related differentially expressed genes (IRDEGs), which belong to the KEGG (Kyoto encyclopedia of genes and genomes) pathways, such as the complement and coagulation cascades, chemokine signalling pathways and toll-like receptor signalling pathways were mainly observed at $24 \mathrm{~h}$ post-infection.
\end{abstract}

Conclusions: Infection with C. irritans resulted in a large number of DEGs in the immune-related tissues of $S$. marmoratus. The rapid and significant response of the S. marmoratus immune signalling pathways following $C$. irritans infection may be associated with their involvement in the immune process.

Keywords: Sebastiscus marmoratus, Cryptocaryon irritans, Transcriptome, Immune system, Signalling pathway

\footnotetext{
* Correspondence: qiandong@nbu.edu.cn

${ }^{1}$ Key Laboratory of Applied Marine Biotechnology, Ministry of Education, Ningbo University, Ningbo 315211, China

${ }^{2}$ Collaborative Innovation Center for Zhejiang Marine High-efficiency and

Healthy Aquaculture, Ningbo University, Ningbo 315211, China
} 


\section{Background}

As a common target species for the fishing industry, the false kelpfish (Sebastiscus marmoratus) is mainly distributed in the Western North Pacific. The small size and ease of feeding have made $S$. marmoratus a target species in artificial breeding programs in China. The widespread occurrence of the marine parasitic disease cryptocaryoniasis has resulted in significant limitations in the aquaculture of these fishes. For example, available data indicate that $S$. marmoratus is a susceptible host to Cryptocaryon irritans [1]. For these reasons, this species of fish is a good candidate in which to study the aetiology and pathogenesis of $C$. irritans. For instance, Sun et al. (2011) first successfully constructed a subculture system of C. irritans with $S$. marmoratus as the host [2]. Previous research has indicated that $C$. irritans infection results in elevated of serum cortisol, glucose contents, accelerate respiratory rate, and reduced food intake in $S$. marmoratus $[1,3]$. However, to date, the patterns of immunological responses in infected $S$. marmoratus has not been thoroughly studied.

Cryptocaryon irritans is an obligate parasitic ciliate that lives in the epithelium of the fish gills, skin and fins, infecting most marine teleosts. To investigate the mechanisms of immune response to $C$. irritans, extensive studies from the physiological and biochemical perspectives at the molecular level have been conducted [4-6]. Recent work has indicated that the infection with sublethal doses of $C$. irritans, or the injection of inactivated C. irritans cells, could not only significantly improve the fish's mucus production and serum antibody titers but also increase the activities of mucus LZM and AKP. Also, the contents of mucus IgM and complement C3, and the protective immune rate are different [7-9]. In recent years, numerous data have been produced regarding gene-level regulation that suggests that immunerelated (IR) factors such as TLR2, MyD88, IL1 $\beta$ [10], PCpis [11], TNF- $\alpha$, MHC I/II, and TGFB1 [12], NCCRP1 [13], TRAF6 [14], IRAK4 [15], IL34/MCSF2, MCSFR1/ MCSFR2 [16], Nrdp1 [17] and Interferon- $\gamma$ [18] in the fish are linked to $C$. irritans infection. Despite this work, the changes in the relative amounts of a few factors are not enough to provide a thorough understanding of the immune responses in infected fish.

A transcriptome is the set of all RNA transcripts in the cells. Transcriptome analysis indicates the level of mRNA of a specific gene in response to stimuli. From this evaluation of the expression (an up or down level of each RNA), functions and activated pathways may be inferred. In recent years, transcriptome analysis has been applied in the studies on the interactions between fish and parasites $[19,20]$. To have a better understanding of C. irritans infection and immunological response of the host, Khoo et al. (2012) developed a cDNA microarray analysis to analyze the stress response of Asian sea bass (Lates calcarifer) to C. irritans infection [21]. With the development of next-generation high-throughput sequencing technique, RNA-seq has also been applied in the studies of the fish-C. irritans interaction. Two recent reports have examined the transcriptome of $C$. irritans infected large yellow croaker (Larimichthys crocea) in IR tissues through RNA-seq $[6,22]$, and a transcriptomic variation analysis on the $C$. irritans locally-infected skin of orange-spotted grouper (Epinephelus coioides) has been reported [23]. These data provide a frame of reference to enhance our understanding of the mechanisms of immunity of fish to $C$. irritans infection at the molecular level, by combining a variety of bioinformatic analyses, such as evolutionary genealogy of genes: nonsupervised orthologous groups (eggNOG), gene ontology (GO), and Kyoto encyclopedia of genes and genomes (KEGG). However, there have been no published studies examining the responses using this approach in other fish species. Furthermore, little is known about the variations in the differentially expressed genes (DEGs) enriched signalling pathways over time following C. irritans infection.

In response to $C$. irritans infection, skin, gills, head kidney, spleen and liver are believed to be the most important immune responsive tissues [17]. Skin showed a local immune response against C. irritans infection [23]. Liver from $C$. irritans-immunized $L$. crocea was the first tissue examined with respect to a comparative gene transcription analysis [22]. In the present study, S. marmoratus were infected with $C$. irritans theronts at a sublethal concentration [1]. RNA-seq was utilized to detect the transcripts in three pooled systemic immune-related tissues of $S$. marmoratus at 24, 48, 72 and 96 h postinfection utilizing bioinformatics analysis of the IRpathways, as well as comparing the variations of all the involved DEGs. Key genes and signalling pathways that are involved as potential regulatory role were further explored.

\section{Methods}

\section{Parasite and experimental fish}

Cryptocarion irritans were obtained from naturally infected Pompano (Trachinotus ovatus, $500 \pm 50 \mathrm{~g}$ ), and $T$. ovatus were then used as the model to establish the passage system. Propagation and collection of tomonts and theronts were conducted as previously described [24].

Sebastiscus marmoratus (45 $\pm 3 \mathrm{~g})$ were purchased from local fisheries in Aaotou, Huizhou City, Guangdong Province, China. No C. irritans trophonts were detected on the gills, skin, or fins of these fish, and no immobilization occurred when $C$. irritans theronts were incubated in fish blood serum. The fish were overfed twice daily (8:00 and 15:00) with mixed wild fish meat that was 
Table 1 Summary of de novo assembly of transcriptomic profiles of Sebastiscus marmoratus

\begin{tabular}{llllllll}
\hline & Total length $(\mathrm{bp})$ & Sequence No. & Max length (bp) & Average length (bp) & N50 & $>$ N50 reads No. & GC (\%) \\
\hline Contig & $147,180,023$ & 434,694 & 28,497 & 338.58 & 524 & 51,710 & 44.40 \\
Transcript & $197,518,635$ & 213,321 & 28,455 & 926 & 1976 & 27,719 & 46.57 \\
Unigene & $58,850,763$ & 33,291 & 28,455 & 1768 & 2756 & 6903 & 49.66 \\
\hline
\end{tabular}

purchased and stored at $-20{ }^{\circ} \mathrm{C}$ until feeding [1]. The water temperature, salinity, light intensity, and photoperiod for aquaculture were $26 \pm 1{ }^{\circ} \mathrm{C}, 29-31 \%$, $1000 \mathrm{Lux}$, and 12 L:12D, respectively.

\section{Experimental design and sample collection}

Active $C$. irritans theronts released from tomonts within $2 \mathrm{~h}$ were collected, and the concentration of theronts was calculated [25]. Sixty healthy fish were challenged with theronts at a dose of 5000 theronts per fish $(96 \mathrm{~h}$ after the infection at 5000 theronts/fish, the survival of S. marmoratus was $85 \%$ ), as previously described [1]. Spleens, head kidneys and livers of 3 fish were sampled for expression analysis at $24 \mathrm{~h}$ (group B), $48 \mathrm{~h}$ (group C), $72 \mathrm{~h}$ (group D), and $96 \mathrm{~h}$ (group E) each time point post-challenge and unchallenged fish were sampled as control (group A). The tissues were immediately placed in Sample Protector for RNA/DNA (TaKaRa, Dalian, China) and then stored at $-20{ }^{\circ} \mathrm{C}$ until RNA extraction.

\section{Extraction of total RNA and sample preparation for RNA-Seq} Total RNA was extracted using Trizol Reagent ${ }^{\oplus}$ (Invitrogen, Carlsbad, CA, USA) following the manufacturer's instructions, and then treated with RNase-free DNase I included with the kit. The RNA concentration of each sample was quantified using an Agilent 2100 Bioanalyzer (Agilent technologies, Santa Clara, USA). Quantity, purity and integrity were determined with a $1.2 \%(w / v)$ agarose gel and with a Nanodrop-1000 spectrophotometer (NanoDrop, Wilmington, DE, USA). High-quality RNA with absorbance ratios at $260 \mathrm{~nm} / 280 \mathrm{~nm}>1.9$ was selected for high-throughput sequencing. The extracted total RNA was resuspended in distilled water and stored at $-80{ }^{\circ} \mathrm{C}$ before use. To obtain the transcriptome data of fish without tissue specificity, different tissues were pooled in equal amounts of RNA as previously described $[6,26,27]$. In this study, each RNA sample was collected from 3 different IR-tissues, and each tissue sample contained a mixture of samples obtained from 3 fish of the same treatment condition. The purified mRNA was then enriched with oligo (dT) conjugated to magnetic beads and fragmented using divalent cations under elevated temperature.

Random primers and reverse transcriptase were used for first strand cDNA synthesis, and the second strand cDNA was synthesized using DNA polymerase I and RNase H (Invitrogen). A paired-end library was constructed from the cDNA synthesized using the Genomic Sample Prep Kit (Illumina, San Diego, CA, USA). Five normalized cDNA libraries were constructed using RNA from groups A-E. The libraries were sequenced on an Illumina Mi-Seq platform.

Assembly and functional annotation of the transcriptome A paired-end (PE) sequencing strategy was used to improve the assembly of the entire transcriptome de novo. Raw PE reads with an average length of $250 \mathrm{bp}$ were generated. The FastQC program (http://www.bioinformatics.babraham.ac.uk/projects/ fastqc/) was used to trim adaptor sequences and remove low-quality sequences (defined as when the percentage of bases with a quality value $\leq 5$ exceeds $50 \%$ in the read). A custom Perl program was used to remove short sequences $(<50 \mathrm{bp})$. Trinity (https://github.com/trinityrnaseq/ trinityrnaseq/ wiki) was used to perform the de novo assembles, and the resulting high-quality sequences were assembled into contigs and transcripts [28]. To reduce data redundancy, TGICL was used to assemble and cluster transcripts with a minimum length of $200 \mathrm{bp}$. The longest sequences in each cluster were reserved and designated as unigenes [29]. GO annotation based on BLASTx hits with the NCBI Nr database was performed using Blast2GO (E-value $<10^{-5}$ ) (https://www.blast2go.com/). The expression levels of differentially expressed unigenes were

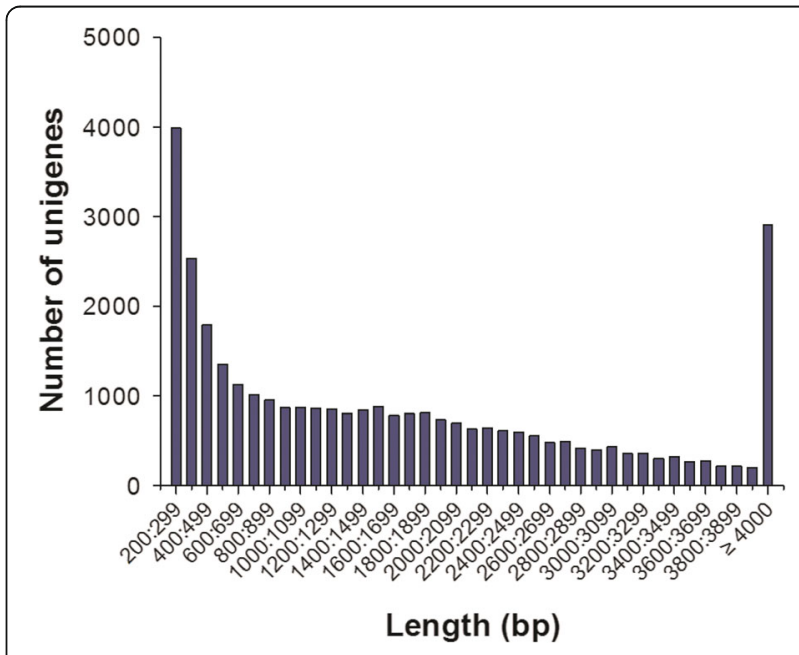

Fig. 1 Transcriptome sequence length distributions of S. marmoratus unigenes. The $x$-axis indicates unigene size and the $y$-axis indicates the number of unigenes with different lengths 
Table 2 Annotation of unigenes of transcriptomic profiles of Sebastiscus marmoratus

\begin{tabular}{lll}
\hline Database & $\begin{array}{l}\text { Number of annotated } \\
\text { unigenes }\end{array}$ & $\begin{array}{l}\text { Percentage of annotated } \\
\text { unigenes in NR top hit }\end{array}$ \\
\hline Swiss-Prot & 29,311 & 88.04 \\
eggNOG & 31,716 & 95.27 \\
GO & 19,698 & 59.17 \\
KO & 11,604 & 34.86 \\
KEGG & 24,202 & 72.70 \\
NR top hit (Total) & 33,291 & 100 \\
\hline
\end{tabular}

annotated using KO analysis (http://www.genome.jp/ kegg/tool/map_pathway2.html). KEGG automatic annotation server (KASS) was used with the default parameters to perform pathway annotation as described previously [27].

\section{Identification of differently expressed genes}

The clean reads from each of the five libraries (A, B, C, $\mathrm{D}$ and $\mathrm{E}$ ) were mapped back to the transcriptome assembly using the Bowtie2 software with default settings. The number of reads aligned to each unigene in the alignment file was determined for each sample. The number of each transcript aligned to a gene was then normalized and calculated using uniquely mapped reads by the RPKM (Reads per kilobase of transcripts per million fragments mapped) method [30]. The differential expression analysis identified DEGs among the five different groups listed above was performed using the DESeq web tool (http://www-huber.embl.de/users/anders/ DESeq). The false discovery rate (FDR) method was used to identify the significance of differences in gene expression. Unigenes with fold changes $>2$ and an adjusted $P$ value $<0.05$ were considered to be differentially expressed genes [31]. The dispersion factor can be understood as the square of the coefficient of biological variation (Additional file 1: Table S1).

\section{Quantitative RT-PCR (qRT-PCR) verification}

To validate the RNA-Seq (Quantification) results, eight genes were randomly selected for qRT-PCR analysis using a SYBR Premix Ex Taq kit (Invitrogen). The RNASeq data indicated that $24 \mathrm{~h}$ post-infection is the peak time-point for the host response to $C$. irritans infection. Thus, group B and the control group were used for the qRT-PCR verification assay. RNA samples used were the same that were used for Illumina library synthesis. The specific primers used are listed in the Additional file 2: Table S2, and $\beta$-actin was used as an internal control. All reactions were performed using technical triplicates. The thermal profile for SYBR Green RT-PCR was $95{ }^{\circ} \mathrm{C}$ for $5 \mathrm{~min}$, followed by 40 cycles of $95{ }^{\circ} \mathrm{C}$ for $15 \mathrm{~s}$, and $60{ }^{\circ} \mathrm{C}$ for $30 \mathrm{~s}$. The relative expression levels of target

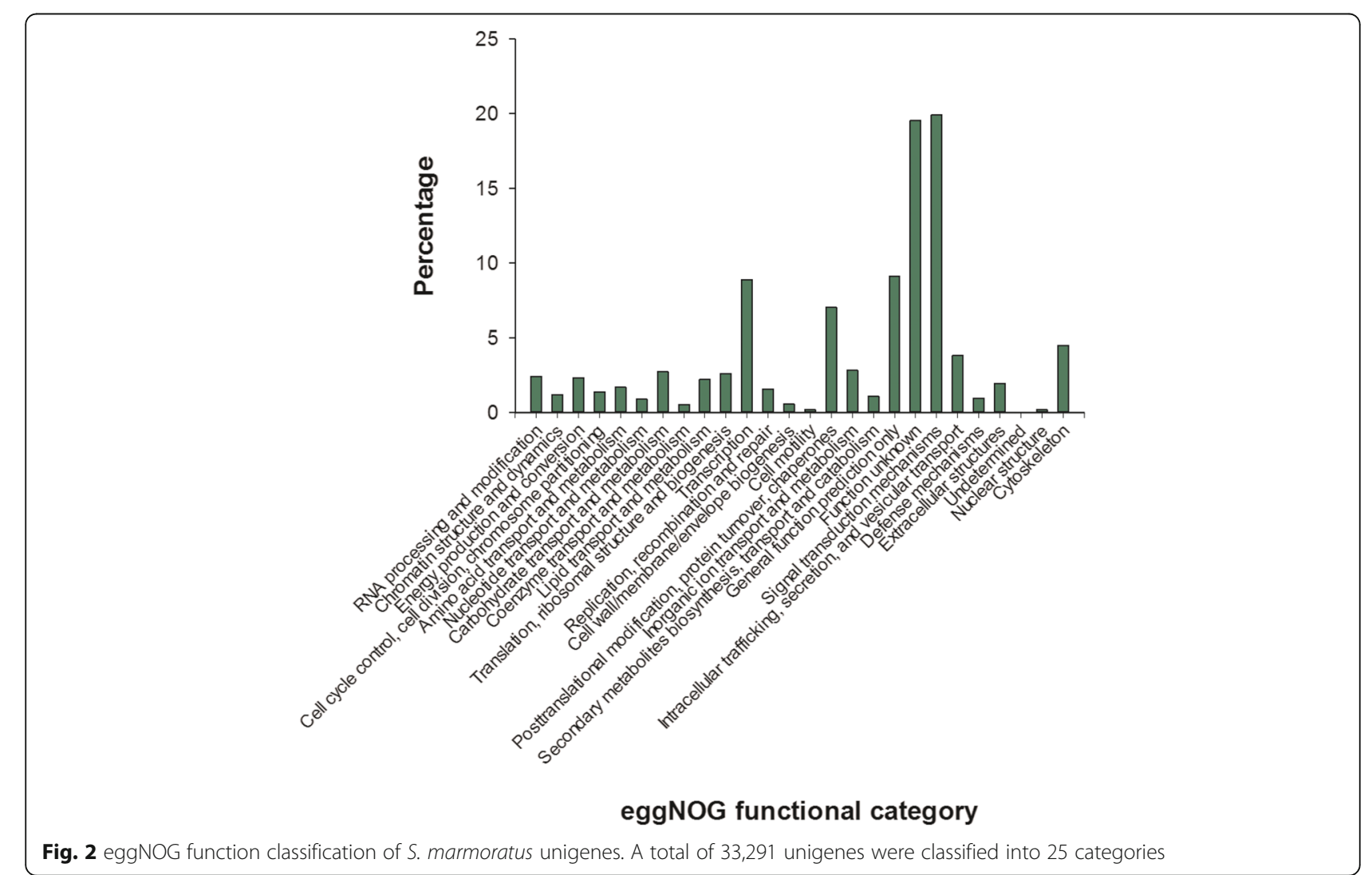


genes were analyzed using the comparative threshold (CT) cycle method as previously described [32]. The RTqPCR data were analyzed using one-way analysis of variance (ANOVA).

\section{Results and discussion}

\section{Sequencing and de novo transcriptome assembly}

The assembled transcriptome consisted of a total of $165,442,302$ paired-end raw reads with an average length of $101 \mathrm{bp}$ (Additional file 3: Table S3). A total of 149,983,397 clean reads were obtained for subsequent analysis (Additional file 3: Table S3). Lowquality sequences and adaptor sequences were eliminated from the original data sequence by quality analysis. De novo transcriptome assembly was performed for the clean reads using Trinity. A summary of all contigs, transcripts and unigene assemblies are presented in Table 1 . The total length and number of contigs were $147,180,023$ bp and 434,694, respectively. The maximum contig length detected was $28,497 \mathrm{bp}$, with an average length of 338.58 bp (N50:524). The observed GC content was $44.40 \%$. The total length and number of transcripts were 197,518,635 bp and 213,321 , respectively. The maximal length of the transcript was 28,455 bp with an average length of 926 bp (N50: 1976) and had a GC content of 46.57\%. The total length and number of unigenes were $58,850,763$ bp and 33,291, respectively. The maximal unigene length was 28,455 bp with an average length of 1768 bp (N50: 2756), and a GC content of $49.66 \%$ (Table 1). The unigene length distribution is displayed in Fig. 1. The majority of sequences ranged from 200

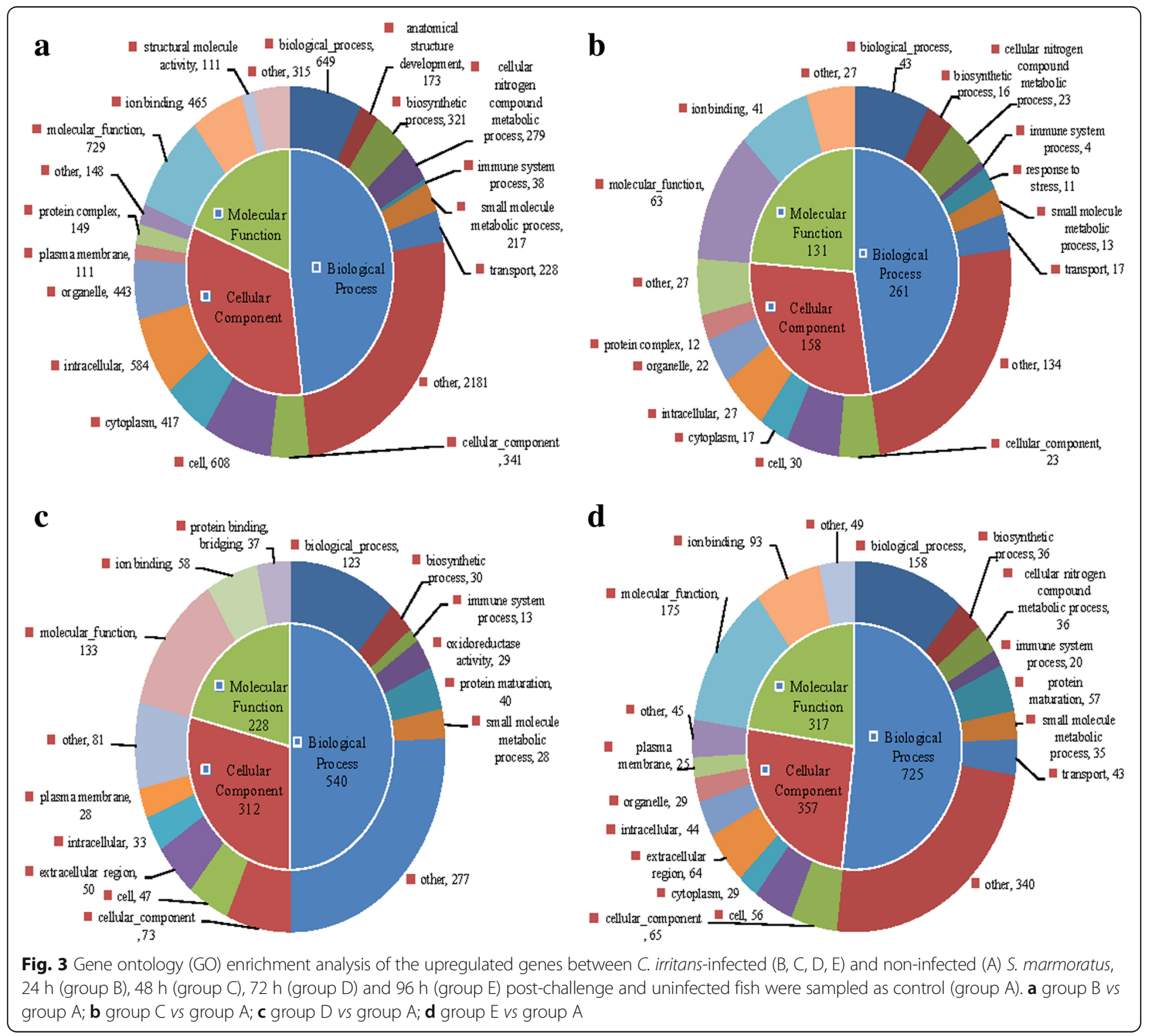


to $299 \mathrm{bp}$ in length. There were 2904 unigenes with length above $4000 \mathrm{bp}$.

\section{EggNOG}

Unigenes were aligned to the eggNOG database for further functional prediction. These data were then classified, and statistical evaluation was conducted for functional predictions of all genes, and the distribution patterns of gene functions of this species were predicted. A total of 31,716 (95.27\%) hits were annotated into 33,291 NR top hit unigenes (Table 2) leading to 25 classifications (Fig. 2). Among the functional classes, signal transduction mechanisms $(7056,19.88 \%)$ were the largest functional group. The smallest two groups were cell motility $(0.17 \%)$ and nuclear structure (0.17\%). Among these, 330 unigenes were assigned to defense mechanisms (Fig. 2).

\section{Identification of $\mathrm{GO}$ enrichment analysis and functional classification by KEGG}

In this study, a total of 19,698 unigenes (59.17\%) (Table 2) were assigned predicted GO terms (Figs. 3 and 4). These terms were summarized into 103 sub-categories under $3 \mathrm{GO}$ terms corresponding to the biological process category (73), cellular component category (16), and molecular function category (14). The unigenes were also categorized using the KEGG database to identify the biological pathways in C. irritans infected $S$. marmoratus. A total of 24,202 unigenes $(72.70 \%$ ) (Table 2) were further annotated by KEGG and classified into 419 known KEGG pathways (Fig. 5).

To identify the DEGs involved in $S$. marmoratus responded to $C$. irritans infection, pairwise comparisons were carried out between the infection groups $(B, C, D$

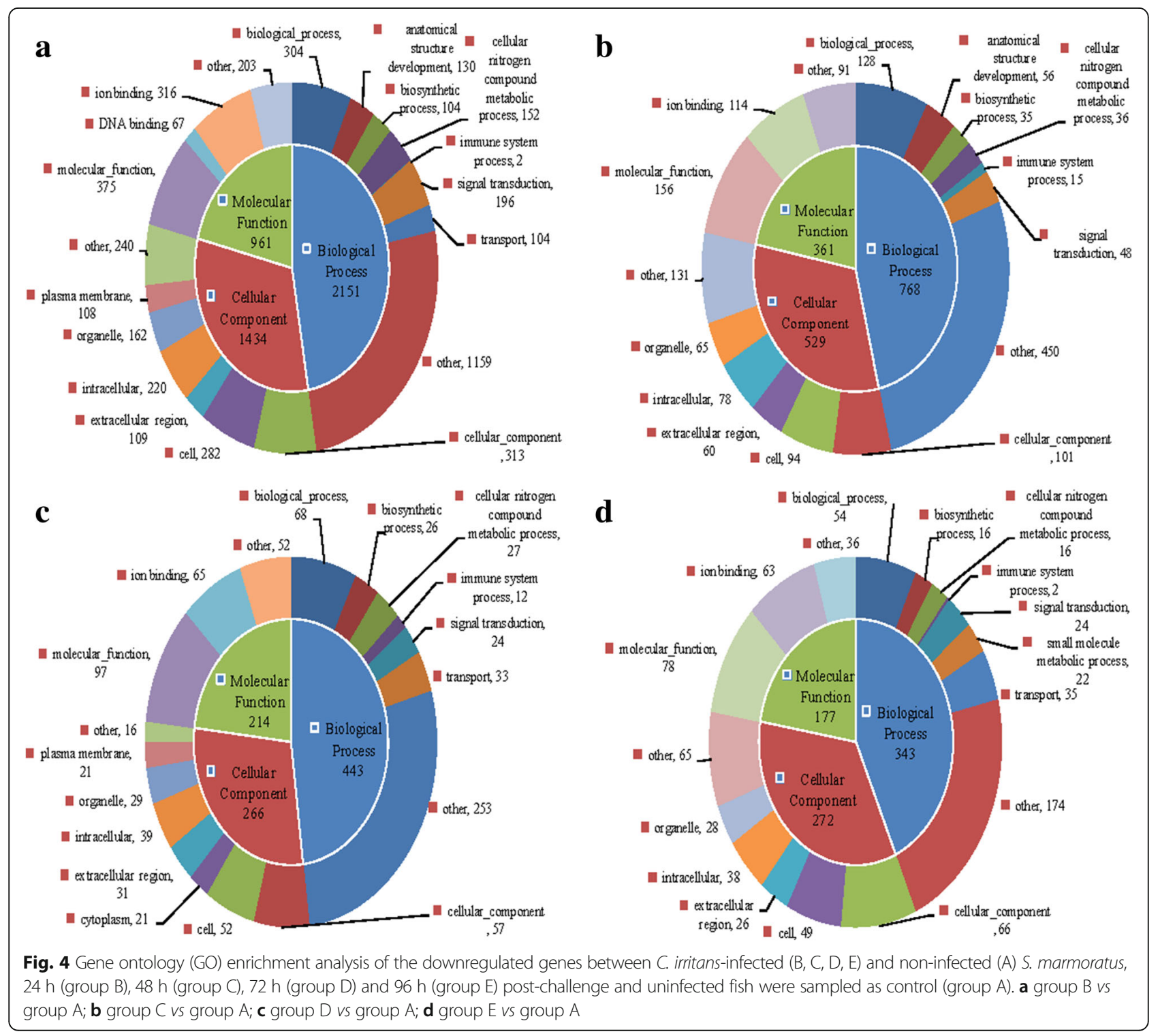




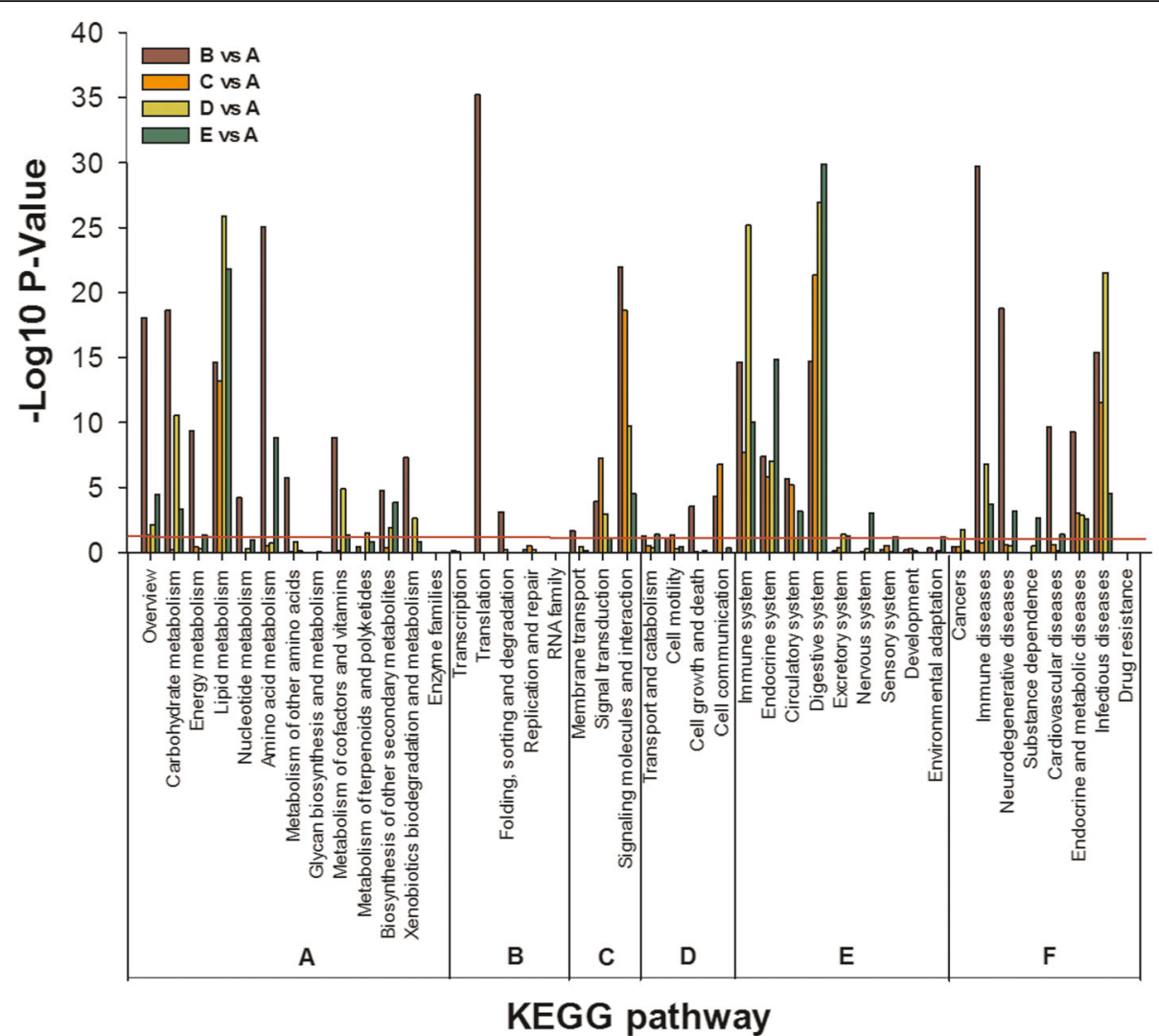

Fig. 5 KEGG pathway enrichment analysis of the differently expressed genes between $C$. irritans-infected (B, $C, D, E)$ and non-infected (A) S. marmoratus. The red line represents $P=0.05$. Key: A, Metabolism; B, Genetic Information Processing; C, Environmental Information Processing; D, Cellular Processes; E, Organismal Systems; F, Human Diseases

and E) and the control group (A) (Figs. 3 and 4). The upregulated DEGs from GO were functionally classified into 94, 68, 72, and 81 sub-categories in groups B, C, D, and $\mathrm{E}$ respectively. The downregulated DEGs were classified into 91, 76, 71, and 69 sub-categories in groups B, C, $\mathrm{D}$, and $\mathrm{E}$ respectively. The molecular function, biological process, and ion binding genes from $S$. marmoratus infected with $C$. irritans were activated. In a B/A pairwise comparison, 3543 (10.64\%) unigenes were differentially expressed, including 1961 upregulated genes in group B. Meanwhile, in C/A, D/A, and E/A pairwise comparisons, only 730, 754, and 814 genes showed differential expression, including $28.36 \%, 52.79 \%$ and $62.78 \%$ genes being upregulated, respectively (Fig. 3). In the immune system process sub-categories, there are significant differences between the infection and control groups. In the B/A pairwise comparison, 77 genes showed differential expression, including 38 upregulated IRDEGs (immune-related differentially expressed genes) in group B; meanwhile, in C/A, $\mathrm{D} / \mathrm{A}$, and $\mathrm{E} / \mathrm{A}$ pairwise comparisons, there were only 19 , 25 and 22 IRDEGs, including 4, 13 and 20 upregulated genes, respectively (Fig. 3). These results indicated that at $24 \mathrm{hpi}$, group B is the key time-point for $S$. marmoratus to combat C. irritans infection. In the 16 IR-genes in enriched KEGG pathways, the results also indicated that the IR-genes enriched signalling pathways were significantly activated or suppressed in the early stages of C. irritans infection. Among these, the most enriched pathways were complement and coagulation cascades, chemokine signalling pathways, and toll-like receptor signalling pathway (Table 3 ).

To validate the expression profiles of genes identified through Illumina sequencing, the relative mRNA levels of the following eight innate immune-relevant genes $(F 9$, CD59, HSP90B, JAM1, C3, F2, CTSL, and FOS) were analyzed by qRT-PCR (Fig. 6). As presented in Fig. 6, the qRT-PCR results correlated well with the results obtained through RNA-Seq.

\section{Analysis of immune-related signalling pathways in in- fected fish}

Transcriptomic studies of the S. marmoratus immune responses to $C$. irritans infection have been conducted. To our knowledge, all of them focus on immune variation at a single timepoint post-infection [6, 22, 23]. It is well established that during the development of $C$. 
Table 3 KEGG pathways with differential expressed immune-related genes enrichment between Cryptocaryon irritans-infected (B, C, $D$, and E) and non-infected (A) Sebastiscus marmoratus

\begin{tabular}{|c|c|c|c|c|c|c|c|c|c|c|}
\hline \multirow{2}{*}{$\begin{array}{l}\text { Pathway } \\
\text { ID }\end{array}$} & \multirow[t]{2}{*}{ Pathway } & \multirow{2}{*}{$\begin{array}{l}\text { Genome } \\
\text { Unigene } \\
\text { number }\end{array}$} & \multicolumn{2}{|c|}{ B vs A } & \multicolumn{2}{|c|}{ C vs A } & \multicolumn{2}{|c|}{ D vs A } & \multicolumn{2}{|c|}{ Evs A } \\
\hline & & & Up & Down & Up & Down & Up & Down & Up & Down \\
\hline ko04640 & Hematopoietic cell lineage & 72 & 7 & 10 & 0 & 4 & 5 & 6 & 5 & 3 \\
\hline ko04610 & Complement and coagulation cascades & 74 & 37 & 12 & 3 & 5 & 35 & 1 & 36 & 0 \\
\hline ko04611 & Platelet activation & 179 & 5 & 19 & 1 & 13 & 4 & 2 & 5 & 4 \\
\hline ko04620 & Toll-like receptor signalling pathway & 106 & 3 & 18 & 0 & 7 & 1 & 10 & 2 & 1 \\
\hline ko04621 & NOD-like receptor signalling pathway & 53 & 3 & 2 & 0 & 3 & 0 & 3 & 2 & 0 \\
\hline ko04622 & RIG-I-like receptor signalling pathway & 69 & 4 & 4 & 0 & 5 & 0 & 6 & 0 & 0 \\
\hline ko04623 & Cytosolic DNA-sensing pathway & 49 & 3 & 5 & 0 & 1 & 0 & 4 & 1 & 0 \\
\hline ko04650 & Natural killer cell mediated cytotoxicity & 86 & 3 & 15 & 1 & 0 & 1 & 1 & 1 & 1 \\
\hline ko04612 & Antigen processing and presentation & 58 & 9 & 14 & 3 & 0 & 0 & 3 & 2 & 0 \\
\hline ko04660 & T cell receptor signalling pathway & 122 & 1 & 10 & 1 & 0 & 1 & 4 & 0 & 0 \\
\hline ko04662 & B cell receptor signalling pathway & 80 & 1 & 4 & 0 & 0 & 1 & 3 & 0 & 2 \\
\hline ko04664 & Fc epsilon RI signalling pathway & 64 & 0 & 4 & 0 & 2 & 0 & 1 & 0 & 1 \\
\hline ko04666 & Fc gamma R-mediated phagocytosis & 114 & 0 & 9 & 0 & 2 & 0 & 2 & 0 & 1 \\
\hline ko04670 & Leukocyte transendothelial migration & 142 & 7 & 10 & 1 & 4 & 0 & 1 & 3 & 1 \\
\hline ko04672 & Intestinal immune network for IgA production & 36 & 0 & 11 & 1 & 1 & 0 & 0 & 1 & 0 \\
\hline ko04062 & Chemokine signalling pathway & 179 & 5 & 21 & 1 & 8 & 1 & 10 & 4 & 3 \\
\hline Total & & 1483 & 88 & 168 & 12 & 55 & 49 & 57 & 62 & 17 \\
\hline
\end{tabular}

Abbreviations: Up upregulated genes, Down downregulated genes

irritans cells, the trophont grows up from $20 \mu \mathrm{m}$ to $300 \mu \mathrm{m}$. Four days post-infection, a large number of trophonts start to leave the host after maturation [33]. However, the changes of immune responses of $S$. marmoratus to C. irritans trophonts at different developmental stages remain largely unknown. Most of the current studies focus on mono-molecular or monopathway variations post-C. irritans infection with the passage of time [17]. In this study, we obtained the most comprehensive data to date through the analysis and bioinformatical enrichment of immune-related signalling pathways, including complement and coagulation cascades, chemokine signalling pathway, and toll-like receptor signalling pathway as previously reported [6, 22, 23]. What's new is that the analysis of transcriptomic variation with the passage of time

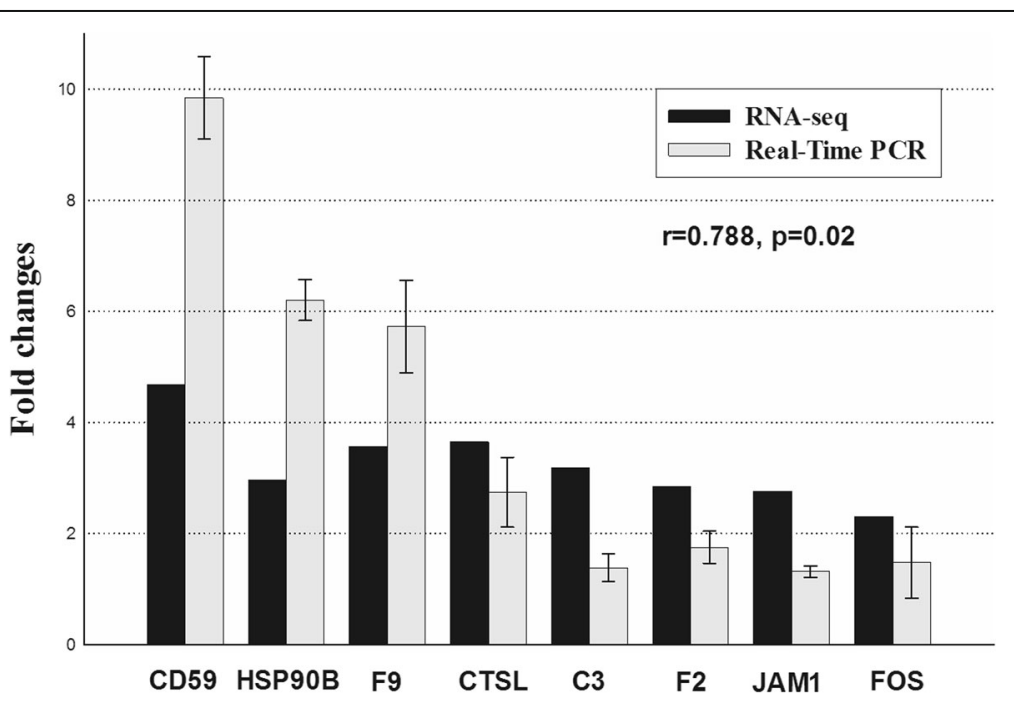

Fig. 6 Validation of RNA-seq data by qRT-PCR. The expression of F9, CD59, HSP90B, JAM1, C3, F2, CTSL, and FOS were detected by RNA-seq (black column) and qRT-PCR (grey column) 
revealed the variation in immune responses and the key time-point for the fish to cope with the C. irritans infection.

\section{Toll-like receptor signalling pathway}

Innate immunity acts as the first line of immune system defence against infection by pattern-recognition

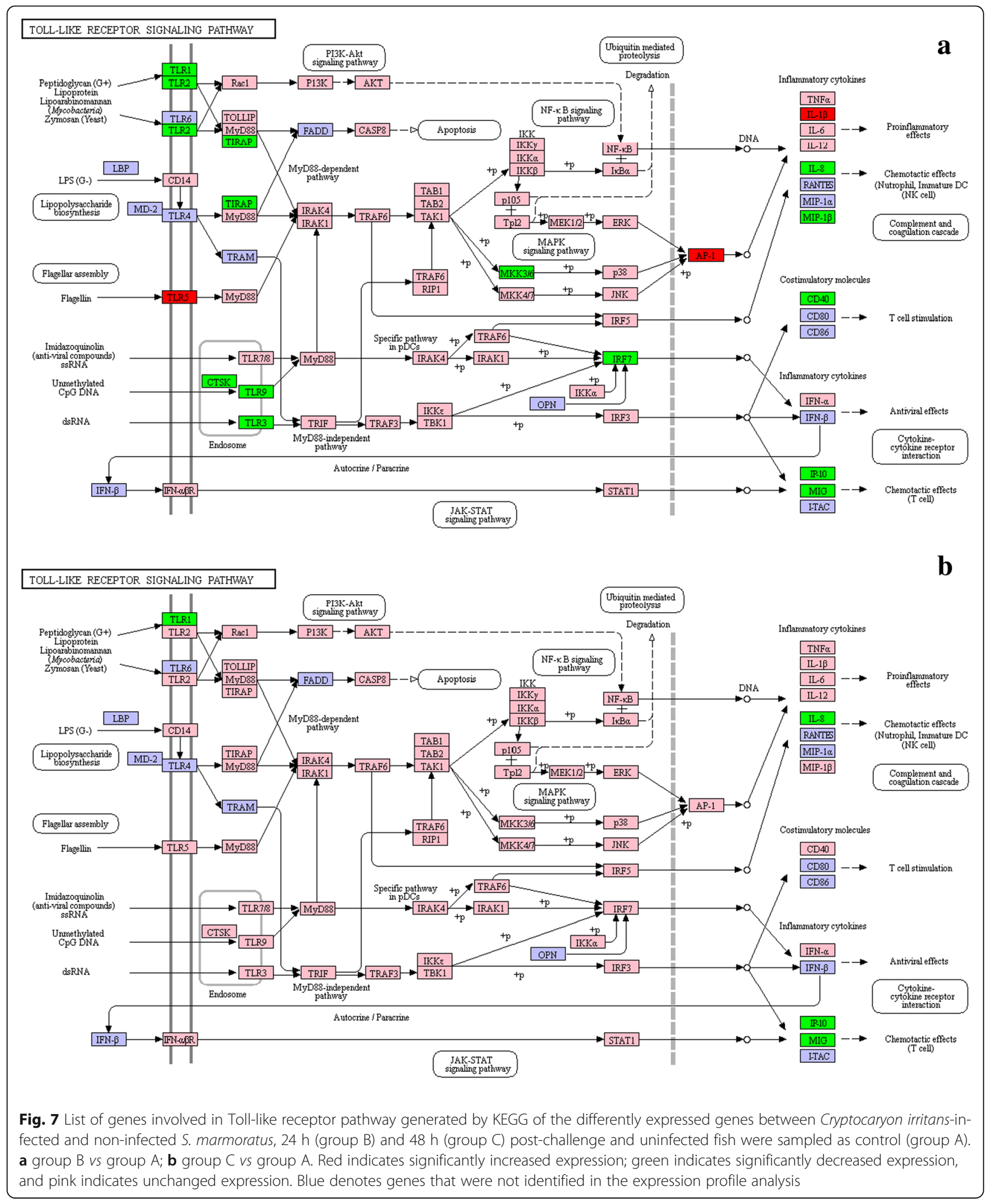


receptors (PRRs). Toll-like receptors, a family of type I transmembrane proteins, are one of best characterized PRRs. It is well established that toll-like receptors recognize conserved pathogen-associated molecular patterns (PAMPs) such as peptidoglycan (PGN), lipopolysaccharide (LPS), lipoprotein (LP), flagellin, and viral dsRNA. Activation of toll-like receptors by the corresponding PAMPs initiates signalling cascades leading to the activation of transcription factors, such as NF- $\mathrm{kB}$, AP-1 and interferon regulatory factors (IRFs). Through a

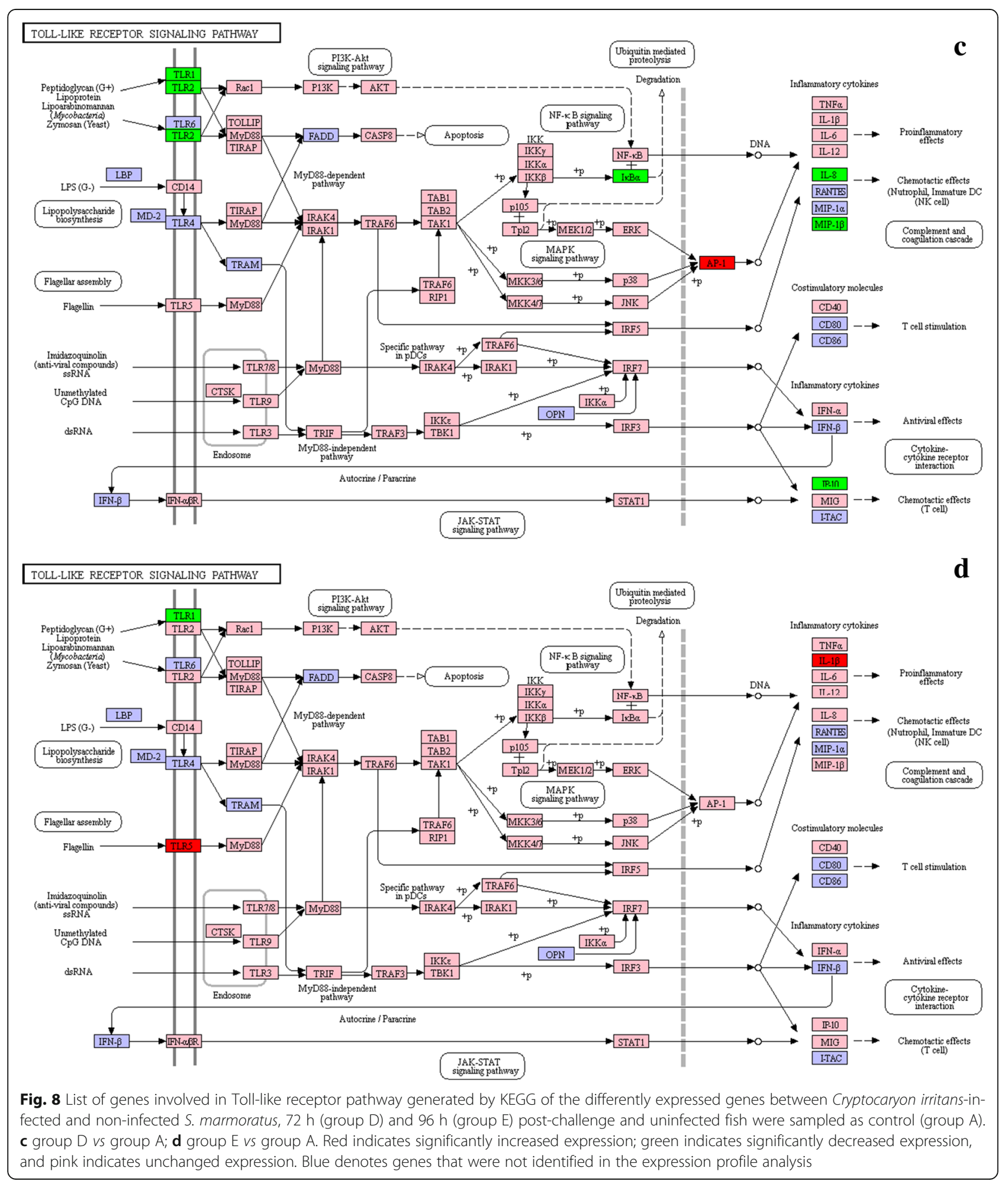




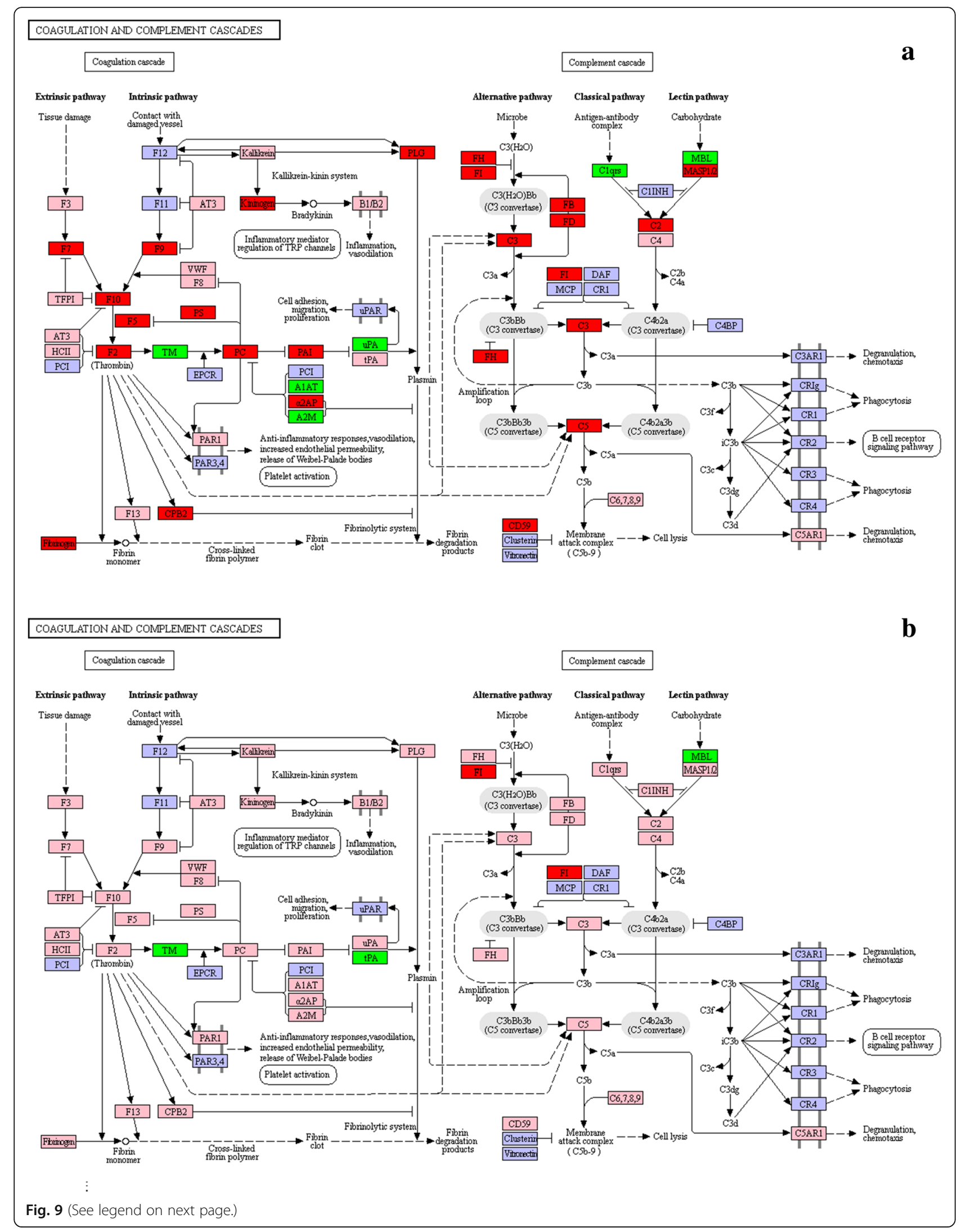


(See figure on previous page.)

Fig. 9 List of genes involved in the complement and coagulation cascades pathway generated by KEGG of the differently expressed genes between C. irritans-infected and non-infected S. marmoratus, $24 \mathrm{~h}$ (group B) and $48 \mathrm{~h}$ (group C) post-challenge and uninfected fish were sampled as control (group A). a group B vs group A; b group C vs group A. Red indicates significantly increased expression; green indicates significantly decreased expression; and pink indicates unchanged expression. Blue denotes genes that were not identified in the expression profile analysis

series of signalling cascades, toll-like receptors can activate various cellular responses, including the production of interferons (IFNs), pro-inflammatory cytokines and effector cytokines. Research on C. irritans infected $E$. coioides indicated that TLR9 and TLR21 transcripts were induced in skin and gill [34]; TLR2 was upregulated in the head kidney and spleen $6 \mathrm{~h}$ post-infection but was downregulated in the skin and gill at most of the tested time points. Furthermore, MyD88, TRAF6, and IL1 were upregulated in immune tissues at most time points $[10,14]$. In addition, a transcriptome sequencing on $C$. irritans infected $L$. crocea showed that TLR5 might be involved in identifying the $C$. irritans' antigen composition, which was corroborated by the finding of Bai et al. (2017), indicating that C. irritans infection could significantly upregulate the expression of EcTLR5s in the gill and spleen [35]. Additionally, it has been shown that the $M y D 88$ gene plays a key role in resistance to $C$. irritans. Upregulated $I K K b, A P-1$ (JUN, FOS), IRF3, IRF7 and STAT1 promoted expression of pro-inflammatory and inflammatory cytokines, such as TNFa, IL1 $\beta, I L 6, I F N a$, and IFN $\beta$. In this study, TLR5, FOS, and IL1 $\beta$ were upregulated $24 \mathrm{~h}$ after C. irritans infection (Fig. 7, Additional file 4: Table S4). Specifically, FOS was upregulated at $72 \mathrm{hpi}$, and TLR5 and IL1 $\beta$ were also upregulated at $96 \mathrm{hpi}$ (Fig. 8, Additional file 4: Table S4). Previous data indicated that in bacterial infection, TLR5 sensing occurs via recognition of a variety of bacterial flagellins serves to augment the activation of NF- $\mathrm{B}[36,37]$. However, this study verified that TLR5 was the only activated receptor, $A P-1$ (FOS) was the key transcription factor, and $I L 1 \beta$ functioning as a proinflammatory cytokine was promoted by $C$. irritans infection. To date, flagellin and profilin [38] are the only known ligands for TLR5. However, whether SmTLR5 could mediate IL1 $\beta$ production in response to C. irritans profilin (https://www.ncbi.nlm.nih.gov/ nuccore/449138907) or which C. irritans ligands had been recognized by $S m T L R 5$ is unknown. Interestingly, expression of TLR1, TLR2, TLR3, TLR8, TLR9, CTSK, TIRAP, MAP2K6, IRF7, IL12 $\beta$, IL8, CCL4, TNFRSF5, CXCL10, and CXCL9 were significantly downregulated $24 \mathrm{~h}$ after infection with $C$. irritans in this study (Fig. 7, Additional file 4: Table S4). A current report has indicated that transcription of TLR21 and TLR9 was downregulated in spleen and head kidney, suggesting that these TLR genes play a role in host anti-C. irritans immune responses [34]. Alternatively, it was suggested that the downregulated expression of the TLR genes-TAK1, PIK3C and PIK3R might be involved in the negative regulation mechanism for an over-inflammatory response following $C$. irritans infection [22].

\section{Cytokine-cytokine receptor interaction and chemokine signalling pathway}

Interleukins (IL) play an important role in the regulation of the immune system during infections [39]. In this study, an upregulation of IL1B, IL1R2 and IL11 were observable at $24 \mathrm{hpi}$ (Additional file 4: Table S4). Current work demonstrated that a significant upregulation of $I L 1 \beta$ indicated that $I$. multifiliis and $C$. irritans infection elicited an inflammatory response in the host $[10,40]$. The biological effects of $I L 1 \beta$ are mediated through interactions with ILIR1 [41, 42], whereas the $I L 1 R 2$ acts as a decoy for $I L 1 \beta$ inhibiting its activity [43]. In the skin and head kidney of rainbow trout (Oncorhynchus mykiss) infected with $I$. multifiliis, transcription of IL1R2 was significantly upregulated [40]. This suggests that IL1R2 may play a role in the prevention of $I L 1 \beta$ entering the systemic circulation from the sites of inflammation [44]. In the cytokine network, IL11 either by itself or in synergy with other growth factors stimulates the proliferation and differentiation of both early and late hematopoietic progenitors [45, 46]. Podok et al. [47] reported upregulation of IL11 expression 6 or 72 hpi in Crucian carp (Carassius auratus gibelio) was induced by Aeromonas hydrophila. In this study, we believe that the upregulation of the IL11 gene might play a role in the immune response to $C$. irritans infection.

Chemokines are a group of small molecules, which regulate the trafficking of different types of leukocytes between cells and thereby playing an important role in the functioning of the immune system as well as homeostasis and development [48]. In mammals, chemokines are classified into four main subfamilies, including $\mathrm{CXC}, \mathrm{CC}$, CX3C, and XC [49]. In a transcriptome study of the Japanese flounder (Paralichthys olivaceus) spleen, 20 chemokines have been identified, which correspond to CC and CXC chemokines and chemokine receptors [29]. In the $L$. crocea liver transcriptome, the significantly upregulated CXCL10/12 and CCL19/20/25 genes might play a crucial role in the immune response to $C$. irritans [22]. In this study, 179 CSP related genes were identified in $S$. 


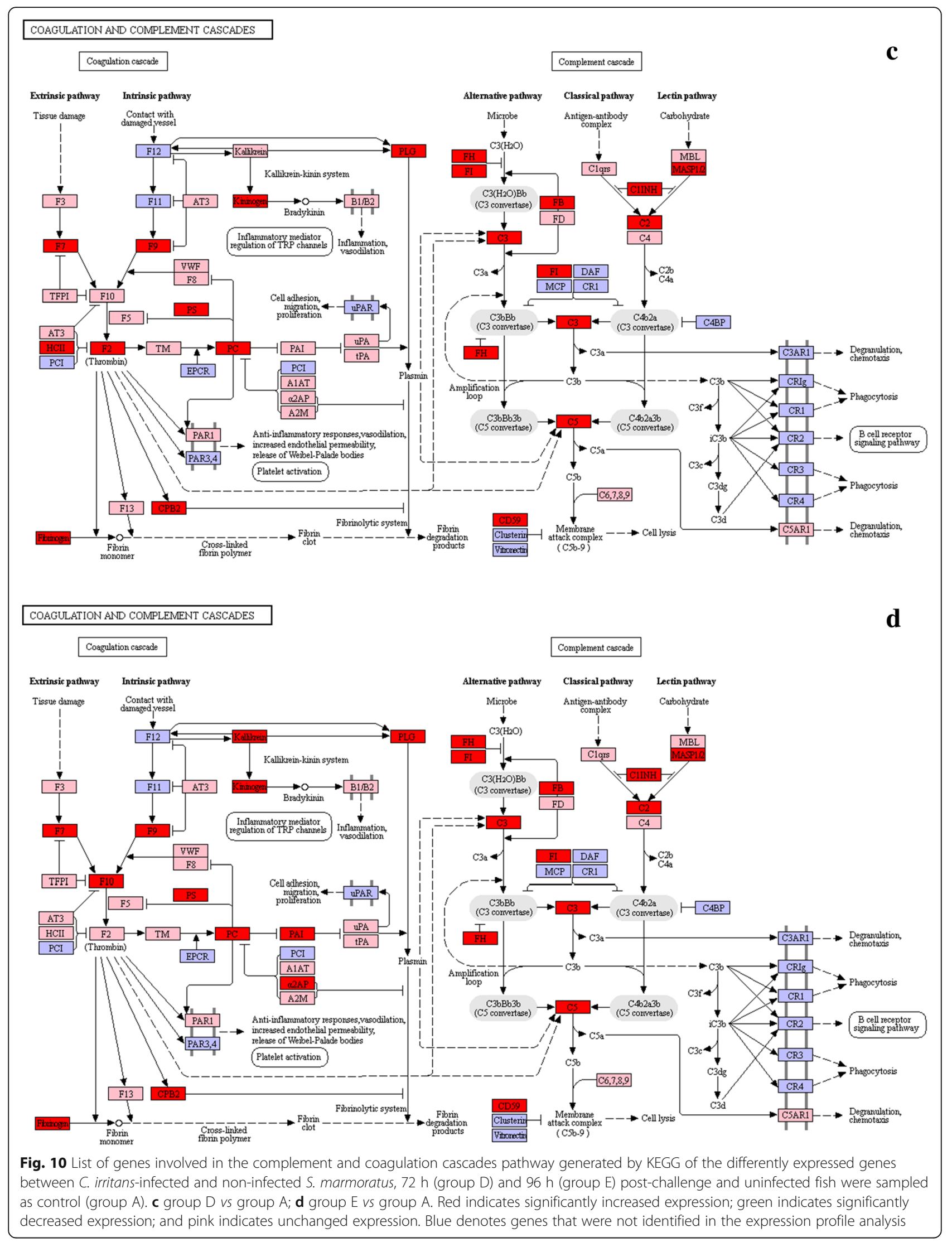


marmoratus systemic tissues; including 7 CXC (CXCL5/6/ 8/9/10/12/13/14), 4 CXC receptors (CXCR2/3/4/5), 4 CC (CCL4/19/20/25), 6 CC receptors (CCR3/4/5/6/7/9) and 1 $\mathrm{XC}$ receptor $(X C R 1)$ were identified for the first time in $S$. marmoratus. However, only 5 in 26, 1 in 9, 1 in 11 and 4 in 7 CSP related DEGs were significantly upregulated at the $24 \mathrm{~h}$ (group B/A), $48 \mathrm{~h}$ (group C/A), $72 \mathrm{~h}$ (group D/ A), and $96 \mathrm{~h}$ (group E/A), post-C. irritans infection, respectively (Additional file 4: Table S4). Additionally, fourteen chemokine signalling pathway related DEGs were identified, among which, CCL1, CCL4 and CXCL9-11 were upregulated in the skin locally infected sites, suggesting teleost skin-associated lymphoid tissue recruits different immune cells, activating a unique immune response pattern [23]. Furthermore, it has been speculated that the downregulated CSP related genes might be involved in the negative regulatory mechanism of the inflammatory response following C. irritans infection [22].

\section{Complement cascade signalling pathway}

Studies showed that, in response to C. irritans infection, the fish body mainly activated its complement system via the alternative pathway (AP) $[6,12]$. This was shown to be largely involved in non-specific immunity during the early stage of infection [12, 21]. When no antigenantibody complex was formed or C1, C4 or C2 was absent in the body, the invading pathogenic substances would directly activate $C 3$, ultimately $C 5-C 9[50,51]$. In a recent study of $I$. multifiliis infected rainbow trout (Oncorhynchus mykiss), C3 expression increased by as much as 5.3 -fold at days 4 and 6 in the skin, and at days 6 and 26 in the spleen [52]. From the L. crocea liver transcriptome, Wang et al. only identified $F H$ and C3like genes, which belongs to the alternative pathway activation. $F H$ and C3-like expression were upregulated through experimental infection with $C$. irritans [22]. In this study, the AP-related genes $F I, F H, F D, F B, C 3, C 5$, $C 7, C 8 A, C 8 B, C 8 G$ and $C 9$ were significantly upregulated (Figs. 9 and 10, Additional file 4: Table S4). C1 complex-C1qrs is the initiation factor for the classical pathway, while $M A S P 1 / 2$ and $M B L$ are the factors known to activate the lectin pathway. The data presented here indicate that, although the expression of $C 2$ and $M A S P 1 / 2$ were upregulated, C1qrs and $M B L$ were downregulated, probably because of the inhibition by C1INH. This could explain why C4 was not activated. However, the membrane-bound complement regulatory protein, $C D 59$, which acts to limit the assembly of membrane attack complex (MAC), was significantly upregulated, to prevent the body's tissue cells from being accidentally damaged by the complement system [53, 54]. On this basis, the results of this study verified the role of the $S$. marmoratus complement alternative pathway in response to C. irritans infection [6].

\section{Conclusions}

Infection with $C$. irritans caused a large number of DEGs in the IR-tissues of $S$. marmoratus. However, with the passage of time after infection, the number of DEGs was significantly reduced from $24 \mathrm{~h}$ to $48 \mathrm{~h}$; then increased again from $72 \mathrm{~h}$ to $96 \mathrm{~h}$. Specifically, the IRDEGs, which belong to the pathways such as complement cascades, cytokine-cytokine receptor interaction, chemokine signalling pathways, and toll-like receptor signalling pathway were mainly found at early signalling following.

\section{Additional files}

Additional file 1: Table S1. The dispersion factor of all of the unigenes between treatment and control groups. (XLSX $3827 \mathrm{~kb}$ )

Additional file 2: Table S2. Primers for eight target immune-relevant genes used for qRT-PCR. (DOCX $14 \mathrm{~kb}$ )

Additional file 3: Table S3. S. marmoratus transcriptome expression profile after C. irritans infection. (DOCX $16 \mathrm{~kb}$ )

Additional file 4: Table S4. Immune systems with differentially expressed genes between $C$. irritans-infected $(B, C, D, E)$ and non-infected (A) S. marmoratus. (DOCX $133 \mathrm{~kb}$ )

\section{Abbreviations}

DEGs: differentially expressed genes; eggNOG: evolutionary genealogy of genes: non-supervised orthologous groups; GO: gene ontology; IRDEGs: immune-related differentially expressed genes; KEGG: kyoto encyclopedia of genes and genomes; qRT-PCR: quantitative real-time polymerase chain reaction; RNA-seq: RNA sequencing

\section{Acknowledgements}

We would like to thank Personal Biotechnology Co., Ltd. (Shanghai, China) for performing the sequencing and preliminary data analysis.

\section{Funding}

This work was funded by the Ningbo University Research Start-Up Fund for the backbone of scientific research (Grant No. 421707390) and the K. C. Wong Magna Fund in Ningbo University.

\section{Availability of data and materials}

Our datasets are presented in the main manuscript or additional supporting files attached. The RNA-seq raw data have been deposited at the NCBI SRA repository under the accession number PRJNA407039.

\section{Authors' contributions}

FY conceived and designed the study; DQ prepared the first draft of the manuscript; FY and DQ provided strategic advice and assisted with the editing of the manuscript. Both authors read and approved the final manuscript.

\section{Ethics approval and consent to participate}

All animal and parasite experiments were performed according to local and central government regulations. All experiments were approved by the Institutional Animal Care and Use Committee of the Ningbo University.

\section{Consent for publication}

Not applicable.

\section{Competing interests}

The authors declare that they have no competing interests. 


\section{Publisher's Note}

Springer Nature remains neutral with regard to jurisdictional claims in published maps and institutional affiliations.

Received: 9 June 2017 Accepted: 30 October 2017

Published online: 21 November 2017

\section{References}

1. Yin F, Gong QY, Li YW, Dan XM, Sun P, Gao QX, et al. Effects of Cryptocaryon irritans infection on the survival, feeding, respiratory rate and ionic regulation of the marbled rockfish Sebastiscus marmoratus. Parasitology. 2014;141:279-86.

2. Sun $Z Y$, Zheng $C F$, Wu XY, Guo GW, Wang $Y Y$, Huang $X H$. The strain and life-cycle of Cryptocaryon irritans isolated from Pseudosciaena crocea cultured in Xiapu, Fujian. J Fujian Normal Univ (Nat Sci Edit). 2011;101-8. (In Chinese).

3. Yin F, Gong QY, Sun P, Tang BJ, Dan XM, Li AX. Stress and immune responses of the marbled rockfish Sebastiscus marmoratus infected with Cryptocaryon irritans. Acta Hydrobiol Sin. 2014;38:681-8. (In Chinese).

4. Colorni A. Aspects of the biology of Cryptocaryon irritans, and hyposalinity as a control measure in cultured gilt-head sea bream Sparus aurata. Dis Aquat Org. 1985;1:19-22

5. Burgess PJ, Matthews RA. Cryptocaryon irritans (Ciliophora): acquired protective immunity in the thick-lipped mullet, Chelon labrosus. Fish Shellfish Immun. 1995;5:459-68.

6. Yin F, Gao QX, Tang BJ, Sun P, Han KH, Huang WQ. Transcriptome and analysis on the complement and coagulation cascades pathway of large yellow croaker (Larimichthys crocea) to ciliate ectoparasite Cryptocaryon irritans infection. Fish Shellfish Immun. 2016:50:127-41.

7. Yambot AV, Song YL. Immunization of grouper, Epinephelus coioides, confers protection against a protozoan parasite, Cryptocaryon irritans. Aquaculture. 2006:260:1-9.

8. Luo XC, Xie MQ, Zhu XQ, Li AX. Protective immunity in grouper (Epinephelus coioides) following exposure to or injection with Cryptocaryon irritans. Fish Shellfish Immun. 2007;22:427-32.

9. Misumi I, Leong JA, Takemura A, Lewis T. Immune protection of Mozambique tilapia (Oreochromis mossambicus) exposed to different infectious doses of ectoparasite (Cryptocaryon irritans). Parasitol Res. 2012; 110:363-72

10. Li YW, Luo XC, Dan XM, Huang XZ, Qiao W, Zhong ZP, et al. Orangespotted grouper (Epinephelus coioides) TLR2, MyD88 and IL-1[beta] involved in anti-Cryptocaryon irritans response. Fish Shellfish Immun. 2011;30:1230-40

11. Niu S, Jin $Y, X u X$, Qiao $Y, W u Y$, Mao $Y$, et al. Characterization of a novel piscidin-like antimicrobial peptide from Pseudosciaena crocea and its immune response to Cryptocaryon irritans. Fish Shellfish Immun. 2013;35: $513-24$

12. Dan XM, Zhang TW, Li YW, Li AX. Immune responses and immune-related gene expression profile in orange-spotted grouper after immunization with Cryptocaryon irritans vaccine. Fish Shellfish Immun. 2013:34:885-91.

13. Huang X, Li Y, Mai Y, Luo X, Dan X, Li A. Molecular cloning of NCCRP-1 gene from orange-spotted grouper (Epinephelus coioides) and characterization of NCCRP-1+ cells post Cryptocaryon irritans infection. Dev Comp Immunol. 2014;46:267-78.

14. Li Y, Li X, Xiao X, Zhao F, Luo X, Dan X, et al. Molecular characterization and functional analysis of TRAF6 in orange-spotted grouper (Epinephelus coioides). Dev Comp Immunol. 2014:44:217-25.

15. Li Y, Mo X, Zhou L, Li X, Dan X, Luo X, et al. Identification of IRAK-4 in grouper (Epinephelus coioides) that impairs MyD88-dependent NF-kB activation. Dev Comp Immunol. 2014;45:190-7.

16. Mo ZQ, Li YW, Zhou L, Li AX, Luo XC, Dan XM. Grouper (Epinephelus coioides) IL-34/MCSF2 and MCSFR1/MCSFR2 were involved in mononuclea phagocytes activation against Cryptocaryon irritans infection. Fish Shellfish Immun. 2015;43:142-9.

17. Zhang DL, Han F, Yu DH, Xiao SJ, Li MY, Chen J, et al. Characterization of E3 ubiquitin ligase neuregulin receptor degradation protein-1 (Nrdp1) in the large yellow croaker (Larimichthys crocea) and its immune responses to Cryptocaryon irritans. Gene. 2015:556:98-105.

18. Chen R, Su Y, Wang J, Liu M, Qiao Y, Mao Y, et al. Molecular characterization and expression analysis of interferon-gamma in the large yellow croaker Larimichthys crocea. Fish Shellfish Immun. 2015;46:596-602.

19. Robledo D, Ronza P, Harrison PW, Losada AP, Bermúdez R, Pardo BG, et al. RNA-seq analysis reveals significant transcriptome changes in turbot
(Scophthalmus maximus) suffering severe enteromyxosis. BMC Genomics. 2014;15:1149.

20. Sutherland BJ, Koczka KW, Yasuike M, Jantzen SG, Yazawa R, Koop BF, et al Comparative transcriptomics of Atlantic Salmo Salar, chum Oncorhynchus keta and pink salmon O. gorbuscha during infections with salmon lice Lepeophtheirus salmonis. BMC Genomics. 2014;15:200.

21. Khoo C, AbdulMurad AM, Kua B, MohdAdnan A. Cryptocaryon irritans infection induces the acute phase response in Lates calcarifer: a transcriptomic perspective. Fish Shellfish Immun. 2012;33:788-94.

22. Wang P, Wang J, Su Y, Mao Y, Zhang J, Wu C, et al. Transcriptome analysis of the Larimichthys crocea liver in response to Cryptocaryon irritans. Fish Shellfish Immun. 2016:48:1-11.

23. Hu Y, Li A, Xu Y, Jiang B, Lu G, Luo X. Transcriptomic variation of locallyinfected skin of Epinephelus coioides reveals the mucosal immune mechanism against Cryptocaryon irritans. Fish Shellfish Immun. 2017;66:398410.

24. Yin F, Gong H, Ke Q, Li A. Stress, antioxidant defence and mucosal immune responses of the large yellow croaker Pseudosciaena crocea challenged with Cryptocaryon irritans. Fish Shellfish Immun. 2015:47:344-51.

25. Dan XM, Li AX, Lin XT, Teng N, Zhu XQA. Standardized method to propagate Cryptocaryon irritans on a susceptible host pompano Trachinotus ovatus. Aquaculture. 2006;258:127-33.

26. Hu J, You F, Wang Q, Weng S, Liu H, Wang L, et al. Transcriptional responses of olive flounder (Paralichthys olivaceus) to low temperature. PLoS One. 2014;9:e108582.

27. Zhang X, Wang S, Chen S, Chen Y, Liu Y, Shao C, et al. Transcriptome analysis revealed changes of multiple genes involved in immunity in Cynoglossus semilaevis during vibrio anguillarum infection. Fish Shellfish Immun. 2015;43:209-18

28. Zhou W, Zhang Y, Wen Y, Ji W, Zhou Y, Ji Y, et al. Analysis of the transcriptomic profilings of mandarin fish (Siniperca chuatsi) infected with Flavobacterium columnare with an emphasis on immune responses. Fish Shellfish Immun. 2015;43:111-9.

29. Huang L, Li G, Mo Z, Xiao P, Li J, Huang J. De novo assembly of the Japanese flounder (Paralichthys olivaceus) spleen transcriptome to identify putative genes involved in immunity. PLoS One. 2015;10:e0117642.

30. Mortazavi A, Williams BA, McCue K, Schaeffer L, Wold B. Mapping and quantifying mammalian transcriptomes by RNA-Seq. Nat Meth. 2008:5:621-8.

31. Li G, Zhao Y, Liu Z, Gao C, Yan F, Liu B, et al. De novo assembly and characterization of the spleen transcriptome of common carp (Cyprinus carpio) using Illumina paired-end sequencing. Fish Shellfish Immun. 2015;44: 420-9.

32. Livak KJ, Schmittgen TD. Analysis of relative gene expression data using real-time quantitative $P C R$ and the $2-\Delta \Delta C T$ method. Methods. 2001;25: $402-8$

33. Ma R, Ni B, Fan XP, Warren A, Yin F, Ultrastructure GFK. Observation on the cells at different life history stages of Cryptocaryon irritans (Ciliophora: Prostomatea), a parasitic ciliate of marine fishes. Parasitology. 2016;143: 1479-89.

34. Li YW, Luo XC, Dan XM, Qiao W, Huang XZ, Li AX. Molecular cloning of orange-spotted grouper (Epinephelus coioides) TLR21 and expression analysis post Cryptocaryon irritans infection. Fish Shellfish Immun. 2012; 32:476-81.

35. Bai JS, Li YW, Deng Y, Huang YQ, He SH, Dai J, et al. Molecular identification and expression analysis of TLR5M and TLR5S from orange-spotted grouper (Epinephelus coioides). Fish Shellfish Immun. 2017;63:97-102.

36. Tsukada H, Fukui A, Tsujita T, Matsumoto M, lida T, Seya T. Fish soluble tolllike receptor 5 (TLR5S) is an acute-phase protein with integral flagellinrecognition activity. Int J Mol Med. 2005;15:519-25.

37. Muñoz I, Sepulcre MP, Meseguer J, Mulero V. Molecular cloning, phylogenetic analysis and functional characterization of soluble toll-like receptor 5 in gilthead seabream, Sparus aurata. Fish Shellfish Immun. 2013; 35:36-45.

38. Salazar Gonzalez RM, Shehata H, O'Connell MJ, Yang Y, Moreno-Fernandez ME, Chougnet CA, et al. Toxoplasma gondii-derived profilin triggers human toll-like receptor 5-dependent cytokine production. J Innate Immun. 2014;6: 685-94.

39. Pérez-Cordón G, Estensoro I, Benedito-Palos L, Calduch-Giner JA, SitjàBobadilla A, Pérez-Sánchez J. Can a parasitic infection modulate the expression of interleukin genes in a fish-myxozoan system? Fish Shellfish Immun. 2013;34:1672. 
40. Sigh J, Lindenstrøm T, Buchmann K. Expression of pro-inflammatory cytokines in rainbow trout (Oncorhynchus mykiss) during an infection with Ichthyophthirius multifiliis. Fish Shellfish Immun. 2004;17:75-86.

41. Stylianou E, O'Neill LA, Rawlinson L, Edbrooke MR, Woo P, Saklatvala J. Interleukin 1 induces NF-kappa B through its type I but not its type II receptor in lymphocytes. J Biol Chem. 1992;267:15836-41.

42. Sims JE, Gayle MA, Slack JL, Alderson MR, Bird TA, Giri JG, et al. Interleukin 1 signaling occurs exclusively via the type i receptor. Proc Natl Acad Sci USA. 1993;90:6155-9.

43. Colotta F, Re F, Muzio M, Bertini R, Polentarutti N, Sironi M, et al. Interleukin1 type II receptor: a decoy target for IL-1 that is regulated by IL-4. Science. 261:472-5.

44. López-Castejón G, Sepulcre MP, Roca FJ, Castellana B, Planas JV, Meseguer J, et al. The type II interleukin-1 receptor (IL-1RII) of the bony fish gilthead seabream Sparus aurata is strongly induced after infection and tightly regulated at transcriptional and post-transcriptional levels. Mol Immunol. 2007:44:2772-80.

45. XX D, Williams DA. Interleukin-11: a multifunctional growth factor derived from the hematopoietic microenvironment. Blood. 1994;83:2023-30.

46. Du X, Williams DA. Interleukin-11: review of molecular, cell biology, and clinical use. Blood. 1997:89:3897-908.

47. Podok $P, X u L, X u D, L u$ L. Different expression profiles of interleukin 11 (IL11), Intelectin (ITLN) and purine nucleoside phosphorylase 5a (PNP 5a) in crucian carp (Carassius auratus gibelio) in response to Cyprinid herpesvirus 2 and Aeromonas hydrophila. Fish Shellfish Immun. 2014;38:65-73.

48. Laing KJ, Secombes CJ. Chemokines. Dev Comp Immunol. 2004;28:443-60.

49. Nomenclature IWSOC. Chemokine/chemokine receptor nomenclature. Cytokine. 2003;21:48-9.

50. Song WC, Rosa Sarrias M, Lambris JD. Complement and innate immunity. Immunopharmacology. 2000;49:187-98.

51. Boshra H, Li J, Sunyer JO. Recent advances on the complement system of teleost fish. Fish Shellfish Immun. 2006;20:239-62.

52. Sigh J, Lindenstrøm T, Buchmann K. The parasitic ciliate Ichthyophthirius multifiliis induces expression of immune relevant genes in rainbow trout, Oncorhynchus mykiss (Walbaum). J Fish Dis. 2004;27:409-17.

53. Huang Y, Qiao F, Abagyan R, Hazard S, Tomlinson S. Defining the CD59-C9 binding interaction. J Biol Chem. 2006;281:27398-404.

54. Wu G, Hu W, Shahsafaei A, Song W, Dobarro M, Sukhova GK, et al. Complement regulator CD59 protects against atherosclerosis by restricting the formation of complement membrane attack complex. Circ Res. 2009; 104:550-8.

\section{Submit your next manuscript to BioMed Central and we will help you at every step:}

- We accept pre-submission inquiries

- Our selector tool helps you to find the most relevant journal

- We provide round the clock customer support

- Convenient online submission

- Thorough peer review

- Inclusion in PubMed and all major indexing services

- Maximum visibility for your research

Submit your manuscript at www.biomedcentral.com/submit

) Biomed Central 